Годищњак Филозофског̄ факулиеиейа у Новом Саду, Къиг̄a ХХХVIII (2013)

Annual Review of the Faculty of Philosophy, Novi Sad, Volume XXXVIII (2013)

Marija Kocić

UDK 341.461.1(497.13 Dubrovnik:560.118),1675/1676“

Filozofski fakultet Univerziteta Originalni naučni rad

u Beogradu

\title{
TRETMAN DUBROVAČKIH POKLISARA NA PORTI KRAJEM VEZIRATA FAZIL AHMED-PAŠE ĆUPRILIĆA (1675-1676)*
}

Do vremena Fazil Ahmed-paše Ćuprilića (1661-1676) komunikacija Porte s drugim državama stekla je formu, koja je ostala na snazi do perioda reformi (tanzimata). Rad je zasnovan na građi iz Historijskog arhiva u Dubrovniku (HAD), koja je poređena sa objavljenim zbirkama dokumenata i onovremenim istorijama i putopisima. Svrha istraživanja je da ukaže na momente, koji su tretman dubrovačkih poslanika činili drugačijim od prijema ambasadora evropskih država (Engleske, Francuske i dr.).

Ključne reči: Dubrovnik, Osmansko carstvo, Ahmed-paša Ćuprilić, Carigrad, Jedrene

Dubrovnik je nakon prosperiteta koji mu je doneo Kandijski rat (1645-1669) ${ }^{1}$ neočekivano pogođen zemljotresom (1667), kada počinje da zapada u krizu. Sredinom XVII veka, shodno tretmanu od strane Porte, Dubrovnik se nalazio u sličnom položaju kao Vlaška, Moldavija i Erdelj (Transilvanija). Svima njima precizno je bio utvrđen iznos harača i drugih obaveza (npr. u slučaju Moldavije voska potrebnog brodogradilištima i sl.) (Ricaut: 111-112). Držanje Dubrovnika za tributara odgovaralo joj je iz više razloga. Dubrovčani su bili dobro obavešteni o dešavanjima na Balkanu i Evropi (Ar1: 45), zbog čega su vremenom postali ,trgovci informacijama", čije je usluge rado koristila Porta, njeni predstavnici u provincijama, a tokom Velikog rata (1683-1699) pojedine hrišćanske države.

Istraživanje je fokusirano na period dubrovačko-osmanskih odnosa koji je u istorijskoj nauci ostao nedovoljno rasvetljen, a koji ujedno predstavlja uvod u razdoblje, kome su ranije generacije istoričara poklonile značajnu pažnju (Zlatar 1977; Самарџић, Р. 1959). Isti period, sa druge strane, bio je obeležen borbom Dubrovnika protiv aspiracija Venecije, usmernih da od Jadranskog mora stvori nostre marum (Самарџић, P. 1962: 460-461). Ušće Neretve (Gabela) postalo je predmet interesovanja Venecije, koja je nastojala da spreči Dubrovnik da ovde prodaje so.

\footnotetext{
gavra1@yahoo.com

Rad nastao kao rezultat istraživanja na projektu Modernizacija zapadog Balkana (ev. br. 177009), koji finansira Ministarstvo prosvete, nauke i tehnološkog razvoja Republike Srbije.

1 Sukob između Venecije i Osmanskog carstva poveden zbog posedovanja Kandije (današnji Krit). On je omogućio, s jedne strane porast obima dubrovačke trgovine, a s druge prodor engleskih, nizozemskih i francuskih trgovaca na Levant, usled povlačenja Venecije.
} 
Iz tog razloga su u leto 1675 . u Jedrene stigla trojica muslimana sa arzuhalom ${ }^{2}$ hercegovačkog sandžak-bega. S njima su poklisari vodili neformalan razgovor o otvaranju skele u Gabeli. Dubrovnik je u jeku pomenutog spora ponudio da otvori luku Ston, od čega bi izvukao korist, ali se na taj korak nije smeo rešiti bez odobrenja Porte. Zbog toga je na Portu otputovao poverljivi čovek alaj-bega ${ }^{3}$ Tasovca, da sa vlastima uredi ovo pitanje (HAD, Acta SMM, Corr., b. XLV, N $^{\circ} 1834 / 3, \mathrm{f}^{\circ}$ 2).

Poslanici Dubrovika slati su povodom redovnog ili vanrednog razloga. Najčešći redovan povod njihovog odlaska na Portu predstavljala je isporuka harača. Međutim, postojalo je niz povoda, zbog kojih se Senat mogao rešiti da pošalje poklisara na Portu. Jedan od njih i da bi iskazao čast povodom određenog događaja, kao što je obrezivanje (sunećenje) sultanovih sinova. Početkom 1675. Marin Kabužić krenuo je u Carigrad da bi prisustvovao sunećenju prvorođenog sina Mehmeda IV (Радонић: 861). On je svoj boravak iskoristio da bi se približio ambasadoru Francuske Šarl Mari Fransoa Olijeu, markizu Nointelu (1670-1679) (Самарџић, H: 40). Nameravajući da otputuje u Francusku tražio je od njega preporuke za Kolbera i Pompona, sekretara spoljnih poslova (Самарџић, P. 1959: 66). Pojedini istoričari isticali su da je glavna namera Marina Kabužića bila pokretanje akcije za oslobođenje od vlasti Osmanlija (Самарџић P. 1959: 66). I pored naprasite naravi dokazao se kao mudar diplomata i uspeo da dobije dozvolu za obnovu kapele u Beogradu, koja je tri godine ranije stradala u požaru (Самарџић, Р. 1959: 65; Самарџић, Р. 1962: 473).

Jednu od posledica specifičnih odnosa razvijanih između Porte i Dubrovnika predstavljala je činjenica da je protokol primenjivan tokom prijema poklisara odstupao od prijema ambasadora evropskih država (Engleske, Francuske i Nizozemske) čije prisustvo jača na Levantu, ali i diplomatsko-konzularna mreža, što pojedini istraživači objašnjavaju njihovim ambicijama prema osmanskom tržištu (Ar1: 44). Ambasadori navedenih država za mesto boravka biraju Peru, koja uz Galatu postaje najznačajnije stecište Evropljana u Osmanskom carstvu (pored Izmira). Suprotno tome, poslanici habsburškog cara, Poljske i Dubrovnika odsedali su u Carigradu (Tournefort, II: 192-193), u kućama koje bi im odredila vlast. Prema Mustafi Selanikiju poslanicima Vlaške, Moldavije, Dubrovnika i Venecije nije priređivan banket prilikom audijencije, zbog toga što su ove države bile „nižeg ranga“ (Ar1: 47-48), drugim rečima, osim Venecije sve su bile njene haračlije.

Novi ambasador Engleske Džon Finč (1672-1681) primljen je u prvu audijenciju juna 1674, u vreme kada se delila plata janičarima, čime ga je trebalo uveriti u snagu i moć osmanske države. Novac je u kovčezima unošen u saraj, dok su janičari čekali u i oko saraja. Određena suma davana je oda-baši svake janičarske ode. Tek nakon što je isplata izvršena Finč je primljen u audijenciju. Njega je prvo primao veliki vezir, nakon čega je organizovan ručak na kome su za zasebnim sinijama sedeli ambasador i njegova pratnja. Nakon toga ambasadora je čauš-baša ${ }^{4}$

Arzuhal (arz u hâl) molba, žalba ili predstavka naroda ili grupe ljudi upućenih na Portu.

Alaj-beg (alay-bey) zapovednik spahija u jednom sandžaku (provinciji)

Čauš-baša (çauş-başı) zapovednik čauša na Porti, koji su u određenim trenucima slati u strane države, te su u tom pogledu sticali ranz zvaničnog Portinog glasnika. 
odveo do izdvojenog dela prostorije, gde su naslagani na gomilu stajali kaftani. ${ }^{5}$ Finč i njegovi pratioci morali su da izaberu pojedine primerke, što je smatrano znakom sultanove milosti, i potvrdom njegovog položaja. Tek nakon ovoga izveden je pred sultana u audijenciju, koja je trajala četiri minuta (Abbott: 136, 145).

Porta je plaćala troškove stranih poslanstava tokom boravka na njenoj teritoriji. Poslanstva su, zavisno od prirode njihovog posla, mogla ostati nekoliko dana, nedelja ili meseci. Međutim, kada su Francuska i Engleska počele da usmeravaju trgovce ka ovom delu sveta, njihovi predstavnici počeli su se duže zadržavati u Carigradu. Zbog toga ove države tokom XVII veka grade rezidencije i uređuju način isplate ambasadora i konzula (delom iz budžeta, a delom od prihoda Levantskih kompanija). Sa tributarnim državama, kao i Habsburškom monarhijom ili Poljskom, čiji su poslanici dolazili u Carigrad po pitanju rešavanja sporova ili objave rata, ovo nije bio slučaj. Njihovo i izdržavanje predstavnika vazalnih država, uključujući i dubrovačku, padali su na račun Porte. Zbog toga je vlast stvorila „fond“ u koji je izdvajano milion akči godišnje za ove potrebe (Arı: 46). Defterdar je iz njega namenio 200 akči dnevno Rafu Gučetiću i Orsatu Ranjini, koji su u leto 1675. doneli harač, dok budu boravili u Jedrenu (HAD, Acta SMM, Corr., b. XLV, N ${ }^{\circ}$ $1834 / 3, f^{\circ} 3$ ).

Shodno praktikovanom maniru Porta je imala obavezu da poslanicima svih rangova (ambasadori, konzuli) obezbedi smeštaj. Za poklisare koji su 1675. doputovali u Jedrene predviđena je kuća jevrejskog trgovca Davida Abuafa. U jednom istoriografskom prikazu navedeno je međutim, da je 6 puta, koliko je za 25 godina boravio u Carigradu, Marin Kabužić odseo u kući tumača carskog rezidenta Mark Antonija Mamuke dela Toresa (Lodi [87]). ${ }^{6}$

Kuga koja je pustošila osmansku državu tokom leta 1675. uticala je na primenu diplomatskih manira. Verski praznik koji je u bio u toku umesto u radost pretvorio se u sahrane i naricanje. Dnevno je u Jedrenu, koje je tokom većeg dela vladavine Mehmeda IV (1648-1687) figuriralo kao nezvanična prestonica, umiralo preko 100 ljudi. U osmanskoj državi nije postojala druga zaštita sem begstva (HAD, Acta SMM, Corr., b. XLV, $\mathrm{N}^{\circ} 1834 / 3, \mathrm{f}^{\circ}$ 1). Zbog kuge Jedrene su napustili svi stranci. Džon Finč prešao je u grčko selo Karagač, milju i po udaljeno od grada (Abbott: 136). Ni sultanov harem, koji se s njim preselio u Ak Binar, nije ostao pošteđen. Jedna sultanova robinja, za koju je navedeno da je bila njegova miljenica, umrla je, kao i dva ič-oglana (HAD, Acta SMM, Corr., b. XLV, N ${ }^{\circ} 1834 / 3$, f ${ }^{\circ} 1$ ). Međutim, stranci koji su prešli u Bosna Koj, tridesetak ljudi, do početka oktobra bili su mrtvi, izuzev Italijana Armelinija (HAD, Acta SMM, Corr., b. XLV, N 1834/4, $\mathrm{f}^{\circ} 1$ ), i dubrovačkih poklisara. Jedrene je napustio i defterdar, čija je služba zahte-

Kaftan predstavlja izuzetno skup primerak osmanske odeće, ubrajan u gornje odevne predmete. Zbog značaja ubrajao se u „odoru časti“ (hllat) i vrlo rano se izdvojio kao sastavni deo ceremonije prijema stranih poslanika. Njegovo darivanje smatralo se za potvrdu statusa diplomate. O njmu detaljnije: Коцић 2010: 364-365.

6 Ovo delo nema paginaciju, ali smo mi u cilju tačnog navođenja uveli svoju (u uglastim zagradama). Prva pagina počinje od pasusa „Furono sempre lodati...“, jer shodno praksi primenjivanoj krajem XVII veka poveta i uvodni deo nisu paginisani. 
vala da bude uvek prisutan na Porti (Abbott: 137), zbog čega se boravak poklisara nepredviđeno odužio.

Fazil Ahmed-paša vratio se u Jedrene na insistiranje Džona Finča, koji je nastojao da Porta potvrdi kapitulacije Engleskoj. Ovaj posao nije se mogao urediti bez pristanka i u prisustvu velikog vezira. Zbog toga je Ahmed-paša Ćuprilić odlučio da se vrati u Jedrene 27. jula, nakon čega je organizovan prijem (Abbott: 138140). Popustljivost pokazana u slučaju ambasadora Engleske posledica je približavanja dve države, do čega je došlo tokom Kandijskog rata. Ahmed-paša Ćuprilić nije pokazao, međutim, isti stepen razumevanja za dubrovačke poslanike, koji su morali da sačekaju da kuga prođe.

Kuga u osmanskoj državi ispoljavala je određenu ritmičnost u pojavi, kulminaciji i opadanju. Ona se javljala juna, tako da je do septembra njena istrošenost postajala očigledna, kada se ona pretvarala u vrstu ,zloćudne groznice“. Tada su diplomate mogle da se vrate u Carigrad, kao i osmanski službenici. Rezident habsburškog cara ${ }^{7}$ i mletački bailo ${ }^{8}$ Đovani Morozini (1675-1680) takođe su rešili u isto vreme da otputuju za Carigrad (HAD, Acta SMM, Corr., b. XLV, N 1834/3, $\mathrm{f}^{\circ}$ 2). Poklisari zbog činjenice da su se službenici razbežali po svojim imanjima nisu mogli biti primljeni u zvaničnu audijenciju kod velikog vezira, niti Mehmeda IV. Zbog toga su odlučili da otputuju u Carigrad, gde će moći da steknu naklonost pojedinih službenika, koje će njihove molbe, uz primljene poklone, uslišiti.

Rafo Gučetić i Orsat Ranjina 2. novembra, nakon povratka iz Carigrada, krenuli su da predaju harač, ali nisu mogli biti primljeni kod velikog vezira niti kod sultana. Navedenog dana su u saraju proveli 2 do 3 sata, čekajući da budu primljeni. Obratio im se Aleksandar Mavrokodato, prvi dragoman (tumač) Porte, ${ }^{9}$ saopštivši im da Mehmed IV još uvek okleva da se vrati u Jedrene, već je prešao u selo Hafsu, šest sati udaljeno od grada, gde je nameravao da provede naredne dve nedelje u lovu. Takođe, ni Ahmed-paša Ćuprilić nije bio u gradu, već na svom imanju u njegovoj okolini. Njegov povratak očekivao se za svečnost podele plate janičarima, zakazane za 10 . novembar. Nakon toga vratili su se u kuću Jevrejina Abuafa zajedno sa novcem (HAD, Acta SMM, Corr., b. XLV, N 1834/5, f ${ }^{\circ}$ 2). Tokom boravka u Jedrenu poklisari nisu imali razloga da se žale na tretman od strane osmanskih dostojanstvenika. Posebno su bili zadovoljni ponašanjem kajmakama Jedrena, koji je vodio sve poslove u odsustvu velikog vezira (HAD, Acta SMM, Corr., b. XLV, $\mathrm{N}^{\circ} 1834 / 5, \mathrm{f}^{\circ} 2$ ).

Način prijema poslanstva na Porti tumačen je kao vrsta pravnog čina (arz) (İpşirli, 191). Poslanik je bio u obavezi da daruje poklone, najčešće skupocene tkanine ili predmete izrađene od srebra i zlata. Zbog toga se tokom XVII veka, u

\footnotetext{
Tokom XVII veka Habsburško carstvo slalo je u svojstvu predstavnika na Portu lice u zvanju rezidenta. Sa tom praksom nastavljeno je do 1718. (odnosno mira u Požarevcu) kada Beč u Osmansko carstvo počinje da šalje ambasadore.

8 U mletačkoj diplomatskoj mreži osoba sa zvanjem baila tretirana je u rangu konzula. Jedino je bailo u Carigradu uživao rang ambasadora; Pia Pedani: 176.

$9 \quad$ Nakon smrti Panajota Nikuzija 1673. postao je prvi dragoman (tumač) na Porti. Njegov uticaj vremenom je jačao. On je postao čovek od poverenja narednih nekoliko sultana. Tokom Velikog rata njemu su poveravane i diplomatske misije, kao naprimer u Beču 1688, gde je zajedno sa Zulfikar-efendijom trebalo da utvrdi mir.
} 
vreme pojačanih kontakata Porte sa evropskim državama, sve češće pominje kao sastavni deo ceremonijala peškedži-baša. ${ }^{10} \mathrm{~S}$ druge strane, Porta je darivanje poklona smatrala vrstom ,obaveze“ poslanika, koji je povodom određenog posla dolazio. U osmanskom društvu poklon je činio sastavni deo „lične časti“, zbog čega je smatran za suštinski važan deo etikecije. Iako su evropski izvori, uključujući i dubrovačke, puni jadikovki na pohlepu Portinih službenika, sa stanovišta Osmanlija „zapadnim Varvarima“ nedostajalo je praktičnog znanja o ,prikladnom ponašanju“, koje je podrazumevalo i obavezu darivanja poklona (Reindl-Kiel: 112-114).

U sklopu svojih obaveza Dubrovčani su morali da predaju poklone sultanu, velikom veziru i validi-sultaniji (majci vladajućeg sultana). Spor je, međutim, nastao u vezi prijema kod sultanije, ćerke Mehmeda IV i supruge Musaip-paše, koji je važio za sultanovog miljenika i potencijalnog naslednika velikog vezira. Međutim, majka Mustafe IV bila je odavno mrtva, zbog čega je ova obaveza prenošena na drugu po ugledu sultaniju. Pol Riko zabeležio je da su Dubrovčani bili u obavezi da daruju velikog vezira, kizlar-agu, validu-sultaniju i druge sultanije (Ricaut: 121), kojih je u to vreme bilo 5 - dve u Carigradu a 3 u Jedrenu (HAD, Acta SMM, Corr., b. XLV, $N^{\circ} 1832 / 3$, fo 4).

Poklisari su tumača ${ }^{11}$ poslali ćehaji Musaip-paše za odobrenje da mogu posetiti njegovu suprugu. Planirali su da sultaniji predaju dva svećnjaka, dva namotaja satena i 4 pakovanja ukuvanog voća (HAD, Acta SMM, Corr., b. XLV, N 1834/5, $\mathrm{f}^{\circ}$ 2). Ćehaja, međutim, nije smeo dati odgovor bez odobrenja Musaip-paše. Narednog dana Musaip-paša poslao je čauša dubrovačkom tumaču da se raspita o poklonima. Poklisari su otkrili da planiraju da tokom audijencije Musaip-šašu daruju sa 150 talira i dve srebrne šolje. Njemu se nije sviđala širina dubrovačke darežljivosti, uputivši primedbu da „ono što ne budu predali milom, predaće silom“ (HAD, Acta SMM, Corr., b. XLV, N ${ }^{\circ} 1834 / 5, f^{\circ} 3$ ). Iako je uživao status sultanovog miljenika, Musaip-paša bio je kube-vezir, a ne veliki vezir. Dubrovčani su međutim bili u obavezi da daruju velikog vezira i nijednog kube-vezira.

Musaip-paša iziritiran takvim nastupom planirao je da traži bujurundiju, ${ }^{12} \mathrm{u}$ kojoj bi bili navedeni pokloni, koje su Dubrovčani bili obavezni. Rasprava se pretvorila u prepucavanje između tumača i Musaip-pašinog čehaje. Na kraju su Dubrovčani bili naterani da popuste. Od poklisara je tražen precizan odgovor o tome koje su poklone nameravali predati Musaip-paši a koje njegovoj supruzi. Ćehaji su posredstvom tumača poslali 20 talira da ugovori audijenciju kod Musaip-paše, tokom koje bi bili dostavljeni pokloni i njegovoj supruzi. Poklisari su bili spremni da Musaip-pašu daruju s 1.000 talira, od kojih su ćehaji trebali odmah predati 100 . Sultaniji su namenili 4 namotaja satena, isto toliko namotaja druge tkanine i dve

\footnotetext{
Jedini od savremenika iz Evrope koji je navedenoj službi posvetio određeno mesto bio je Tomas Dalam; Bent: 258, 260. Pomenuti putnik naziv ove službe pravilno dovodi u vezu sa izrazom za poklon (tur. peşkeş).

11 Dragomani (tumači) nametnuli su se kao nužnost u komunikaciji Porte sa drugim državama. Prvi su ih počele praktikovati italijanske države (Venecija i Đenova). Tokom XVII veka od njih je zavisio i ishod pokrenutog posla, zbog čega je njihov ugled naglo porastao. Dubrovačka republika kao i sve ostale države koje su komunicirale sa osmanskim vlastima dobijali su od Porte dragomane.

12 Bujuruldija (buyuruldu) predstavka nižih organa vlasti upućena višim, odnosno Porti.
} 
srebrne šolje, dok su ćehaji za pokazanu predusretljivost spremili namotaj satena, isto toliko druge tkanine i srebrnu šolju. Od ugovorenih 1.000 talira Musaip-paši odmah je poslato 125 talira (HAD, Acta SMM, Corr., b. XLV, $\mathrm{N}^{\circ} 1834 / 5$, f $\mathrm{f}^{\circ}$ ).

Slučaj sa Musaip-pašom u sebi krije dva elementarna motiva koji predstavljaju i objašenjenje celog dođađaja. Jedan se svodio na značaj poklona u protokolarnoj etikeciji, a drugi na individualnu prirodu pojedinaca koji su zauzimali najznačajnija mesta u osmanskoj upravi. Zbog ugleda sultanovog miljenika, što mu je davalo prioritet nad ostalim vezirima, Musaip-paša smatrao je da od Dubrovčana može „iznuditi“" poklone veće vrednosti, što je ujedno krepilo njegovu sujetu. Ovo, međutim, predstavlja redak slučaj da je došlo do ovakve omaške. Precizno je bila utvrđena visina harača, koji je ova država trebala da plati i lica, kojima su pokloni bili namenjeni. Prema Polu Rikou on je iznosio 12.500 dukata godišnje. Međutim, kada se dodaju pokloni dostojanstvenicima harač je obično iznosio 20.000 dukata (Ricaut: 121). Takođe, on na nijednom mestu ne pominje darovanje ostalih kube-vezira, što je Musaip-paša u tom trenutku bio.

Nakon što su poklisari tokom nove audijencije na Porti predali harač, dobili su od velikog vezira 24. novembra odobrenje da defterdar može izdati potvrdu o upla-

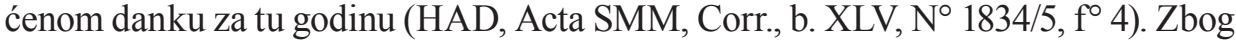
toga su oni ponovo morali da posete saraj. Tom prilikom darovali su dva namotaja satena, isto toliko druge tkanine i jednu srebrnu šolju. Sa svoje strane od Porte, sem ranije darovanih kaftana, ovog puta nisu dobili ništa (HAD, Acta SMM, Corr., b. XLV, $\mathrm{N}^{\circ} 1834 / 5, \mathrm{f}^{\circ} 5$ ).

Kraj 1675. obeležila je smena na upravnim položajima. Uklonjen je hercegovački sandžak-beg, a na njegovo mesto postavljen Veli-paša, poreklom iz Anadolije. Uklonjen je i defterdar bosanskog pašaluka (HAD, Acta SMM, Corr., b. XLV, $\mathrm{N}^{\circ} 1834 / 5, \mathrm{f}^{\circ}$ 5). Rafo Gučetić i Orsat Ranjina nastojali su da privole Portu da ne dopusti da se otvori skela na Gabeli. Na pitanje zbog čega ne mogu dopremati so na Gabelu odgovorili su da put od Dubrovnika do Gabele, udaljene dva dana, vodi kroz visoke planine, i bez ikakve je zaštite (HAD, Acta SMM, Corr., b. XLV, $\mathrm{N}^{\circ}$ 1834/4, $\mathrm{f}^{\circ}$ 2). U Jedrene je 5. oktobra stigao i pastorak bega Tasovca iz Carigrada (HAD, Acta SMM, Corr., b. XLV, $\mathrm{N}^{\circ} 1834 / 4, \mathrm{f}^{\circ} 3$ ). Međutim, početkom naredne godine Dubrovnik je počeo da popušta. Od njega je potekao predlog da se so na Gabeli iz Venecije dostavlja morem a iz Dubrovnika kopnenim putem (Радонић: 868).

U leto 1676. Franjo Gradić i Marin Gučetić od Senata izabrani su da odnesu harač na Portu. U Pljevljima, gde se nalazio saraj hercegovačkog sandžak-bega, izbila je kuga. Zbog toga je sandžak-beg izneo saraj na Jezera. ${ }^{13}$ Tu se sastao krajem jula sa poklisarima. Iz razgovora sa Mataradži-pašom oni su saznali da se sultan nalazi u Carigradu, dok je vojska bila ulogorena u Uskudaru, ${ }^{14}$ spremna da krene u rat (HAD, Acta SMM, Corr., b. XLV, N 1832/2, fo 9). Ahmed-paša Ćuprilić ostao je uz sultana (HAD, Acta SMM, Corr., b. XLV, $N^{\circ} 1832 / 2$, f ${ }^{\circ} 10$ ).

Mesto (položaj) u Drobnjacima.

14 Deo Carigrada na maloazijskoj obali Bosfora. Ovde se obično okupljala vojska iz maloazijskih provincija, namenjena ratištu u evropskom delu države. 
Četiri dana zadržali su se u mestu Ponte Pikolo, ${ }^{15}$ jer nisu imali obezbeđeni smeštaj u Carigradu (HAD, Acta SMM, Corr., b. XLV, $\mathrm{N}^{\circ} 1832 / 3$, f ${ }^{\circ} 1$ ). Odavde su se javili Luki Barki, Napolitancu koji je služio kao njihov dragoman, da im obezbedi smeštaj. Ustupljena im je kuća u delu grada poznatom kao Balat, ${ }^{16} \mathrm{u}$ vlasništvu Turaka, koji su za ponuđenu sumu pristali da je dele sa poklisarima. Jevreji koji su ranije ustupili kuću sada su tražili 500 talira za njihov smeštaj. Na ovome se angažovao i kajmakam Carigrada, koji je poslao svog ćehaju poklisarima da sa njima uredi mesto njihovog boravka.

Kako su ga opisali, saraj je predstavljao „zvaničnu konfuziju“. Poklisarima je bilo teško da otkriju gde njegovi službenici borave. U toku dana zaticali su se na desetak mesta. Ćehaja velikog vezira nalazio se u Uskudaru, a Fazil Ahmed-paša $\mathrm{u}$ delu grada poznatom kao Fundukli. Zbog toga je predstavljalo veliki napor da se zakaže audijencija, izuzev rano izjutra ili kasno uveče, kada su se oni vraćali u saraj. Takođe, svi oni posedovali su po nekoliko saraja (uređenih po ugledu na slutanov) zbog čega su rezidenti i ambasadori, ukoliko bi hteli da zakažu prijem, morali da znaju gde se oni nalaze (HAD, Acta SMM, Corr., b. XLV, N 1832/3, $\mathrm{f}^{\circ}$ 4). Oni su u Cairgrad stigli 13. septembra, da bi ih tri dana kasnije primio Ahmed-paša Ćuprilić (HAD, Acta SMM, Corr., b. XLV, N 1832/4, fo 1). Tokom prijema, shodno protokolu, počašćeni su kafom, šerbetom ${ }^{17}$ i kaftanima (HAD, Acta SMM, Corr., b. XLV, N $1832 / 3, \mathrm{f}^{\circ} 3$ ).

Ćehaja velikog vezira poslat je 18. septembra 1676. poklisarima da javi da je audijencija je zakazana za 21. septembar (HAD, Acta SMM, Corr., b. XLV, ${ }^{\circ}$ 1832/4, f ${ }^{\circ}$ 1). Ukoliko su se nadali da će ona proteći u savršenom redu prevarili su se. Novi haznadar ${ }^{18}$ nije hteo da primi 600 ungara $^{19}$ proglašenih za ,picioli et scarsi, a dua per cento" (HAD, Acta SMM, Corr., b. XLV, N 1832/4, f ${ }^{\circ}$ 1). Zbog manjka plemenitih metala za $2 \%$ (od standardne težine) nije želeo pomenuti novac da primi. Poklisari su odgovorili da će mu kasnije dostaviti razliku u ,zdravom“ novcu, čime bi njihov obaveze bile namirene ,u punoj vrednosti“. Haznadar je odbio predlog, zahtevajući da harač odmah bude isplaćen u celom iznosu. Ćehaja ovim više nije želeo da se bavi jer je trebalo da otputuje za Jedrene i pripremi saraj za sultanov povratak. Ahmed-paša Ćuprilić koga su godine gazile, u međuvremenu je dobio novi napad vodene bolesti, što ga je sprečilo da se umeša u incident (HAD, Acta SMM, Corr., b. XLV, N 1832/4, fo 1).

15 Ponte Picolo (Mali Most) sreće se u mnogim izvorima, pre svega putopisima tokom XVIII veka. Engleski, kao i putnici iz ostalih zemalja, koji su putovali za Carigrad, u svojim itinerarijumima beležili su italijansku varijantu imena ovog mesta. Prva stanica putnicima nakon napuštanja Carigrada. Mesto je bilo smešteno na putu između Carigrada i Selimvrije (tur. Silivri).

16 Balat predstavlja četvrt u Carigradu, u kome tokom ovog perioda, a i kasnije sve češće odsedaju diplomate, posebno iz onih država koje nisu imale svoje rezidenciju u ovom gradu.

17 Kafa tokom XVII veka i pored oštrih prohibijcija biva prihvaćena od osmanskog društva i postaje sastavni deo svakodnevice. U ophođenju s diplomatama obavezno je služena. S druge strane, šerbet predstavlja tradicionalno piće Osmanlija. O njemu videti: Коцић 2010: 324-325.

18 Haznadar reč izvedena od značenja blagajne (hazne), i označava lice koje je njome upravljalo

19 Ongar (vulgarizovano ungar) - zlatni novac kovan u Ugarskoj odnosno Habsburškoj monarhiji, koga je Porta prihvatala kao validno sredstvo plaćanja. 
Mustafa IV koji se spremao na povratak u Jedrene, planirao je sredinom oktobra 1676. povratak u Carigrad, gde je trebala biti proslavljena svadba njegove ćerke i Kara Mustafa-paše, tadašnjeg kajmakama Carigrada (HAD, Acta SMM, Corr., b. XLV, $\mathrm{N}^{\circ} 1832 / 4, \mathrm{f}^{\circ}$ 2). U to vreme bila je opšte privaćena praksa da veziri grade svoje saraje po ugledu na sultanov. Zbog toga je veliki vezir izdao Kara Mustafa-paši da sagradi takav saraj, za šta je izdvojeno 1.600 kesa novca (HAD, Acta SMM, Corr., b. XLV, $\mathrm{N}^{\circ} 1832 / 4, \mathrm{f}^{\circ}$ 3). Ovo otkriva da je do tada uticaj Musaip-paše, koji je prethodne godine poklisarima najviše pravio problema, vidno opao, zbog čega su i incidentne situacije sa njim izostale. Ujedno isti događaj otkriva i novog kandidata za naslednika Ahmed-paše Ćuprilića.

Diplomate koje su slale evropske države našavši se u drugačijoj socijalnoj klimi nastojale su da među sobom pokazuju određenu dozu respekta. Kroz kapitulacije strani poslanici izborili su se za pravo da svoje poslove mogu slobodno da obavljaju sve dok oni nisu zadirali u interese Porte. Opšte je prihvaćen običaj da nakon dolaska novog diplomate ostali predstavnici izađu i pozdrave ga, ili da organizuju ručak u njegovu čast. Nakon što su Franjo Gradić i Marin Gučetić stigli u Carigrad prvo ih je posetio rezident Nizozemske Justin Kolijer (1667-1680). Istog dana ih je posetio i ambasador Francuske markiz de Nointel (HAD, Acta SMM, Corr., b. XLV, $\mathrm{N}^{\circ}$ 1832/4, f ${ }^{\circ}$; Самарџић, H: 40). Narednog dana rezident Đenove Agostino Spinola, a 15 dana kasnije bailo Venecije Đovani Morozini (1675-1680). On se izvinio da je u trenutku kada su poklisari stigli u Carigrad boravio zbog svojih poslova na Crnom moru, zbog čega nije bio na vreme obavešten o njihovom dolasku. Ambasador Francuske, markiz Nointel, u njihovu čast organizovao je banket (HAD, Acta SMM, Corr., b. XLV, $\left.\mathrm{N}^{\circ} 1832 / 4, \mathrm{f}^{\circ} 5\right),{ }^{20}$ u svojoj rezidenciji u Peri.

Krajem oktobra 1676, nakon što su završili sve obaveze poklisari su rešili da otputuju u Jedrene. Put ih je vodio kroz Čorlu, tri dana udaljenu od Carigrada. U njenoj blizini ulogorio se veliki vezir Ahmed-paša Ćuprilić. Nedaleko odatle, u selu Beogradu, odseo je Mehmed IV. Pomenuto selo steklo je tokom XVII veka na značaju kao mesto gde su se povlačili dostojanstvenici zbog vrućine ili kuge. Iznenada odjeknula je vest o smrti Ahmed-paše Ćuprilića. Mehmed IV uspeo je da na njegovo mesto dovede kajmakama Carigrada, i svoga zeta, Kara Mustafu-pašu Ćuprilića (1676-1683) (HAD, Acta SMM, Corr., b. XLV, N 1832/5, f ${ }^{\circ}$ 1). Tokom njegovog vezirata odnosi Porte i Dubrovnika ulaze u novi period, obeležen nastojanjem Mustafa-paše da suzbije poslednji stepen stamostalnosti Dubrovnika (Caмарџић, Р. 1962: 485-504 Самарџић, Р. 1959: 66-74, Zlatar 1977).

\section{REZIME}

Diplomatski maniri koje je Porta primenjivala tokom prijema dubrovačkih poklisara poticao je iz položaja koje je njihova država uživala u osmanskoj viziji „država od značaja“. Zbog toga su njegovi poslanici često bili lišeni svečane cere-

No Nointel je u to vreme posedovao najraskošniji dom u odnosu na ostale diplomate. Njegov opis, koji pruža sliku iz približno istog perioda na koji se odnosi ovo istraživanje u: Magni: 10-14. 
monije tokom prve audijencija, što je primenjivano u slučaju ambasadora Engleske, Francuske i Nizozemske. Dubrovnik nije imenovao stalne ambasadore, zbog čega u Carigradu nije postojala njegova rezidencija. U isto vreme, poklisari nisu trpeli bes Ahmed-paše Ćuprilića, koji je poslednjih godina vezirata mnoge poslove prepustio svojim miljenicima. Slučaj s Musaip-pašom predstavlja do krajnjosti izražene lične želje pojedinih vezira; osobina koja je karakterisala odnos Porte ne samo sa Dubrovnikom, već i s drugim državama. Ahmed-paša Ćuprilić slomljen godinama i vodenom bolešću nije više imao želje da ispoljava samovolju, od čega su jedno vreme posebno trpeli ambasadori Francuske.

\section{IZVORI I LITERATURA}

Historijski Arhiv u Dubrovniku, Acta Sanctae Mariae Maioris, Corrispondenza, busta [kutija] XLV, fasc. 1832 i 1834.

Abbott, George Frederick (1920): Under the Turk in Constantinopole. A Record of Sir George Finch's Embassy 1674-1681. London: MacMillan and Co Limited.

Arı, Bülent "Early Ottoman Diplomacy: Ad Hoc Period" u: Yurdusev, Nuri (ur.) (2004): Ottoman Diplomacy: Conventional or Unconventional. Basingstoke: Palgrave Macmillan.

Bent, Theodore (1893): Early Voyages and Travel in the Levant. I. - The Diary of master Thomas Dallam 1599-1600. II. - Extracts from the Diaries of dr. John Covel, 1670-1679. With some Account of the Levant Company of Turkey Merchants. London: Printed for the Hakluyt Society.

Zlatar Zdenko (1977): „Kara Mustapha and the Republik of Dubrovnik (1677-1678): a New Interpretation“, Balcanica 8.

İpşirli Mehmet, „Osmansko državno uređenje“ u: İhsanoğlu Ekmeleddin (pr.) (2004): Historija osmanske države i civilizacije. Sarajevo: Orijentalni institut u Sarajevu, Posebna izdanja, knj. 26.

Коцић, Марија (2010): Оријенйализаиија майеријалне кулииуре на Балкану. Османски иериод XV-XIX век. Београд: Филозофски факултет \& Hesperiaedu.

Lodi, Giulio (1701): L'immortalità del cavalier Marc Antonio Mamuca della Torre. Vienna: App. Andre Heyinger.

Magni, Cornelio (1692): Quanto di più curioso e vago. Hà potuto raccorre. Nel secondo biennio da esso consumato in viaggi, e dimore per la Turchia. Parma: Per Alberto Pazzoni, e Paolo Monti.

Радонић Јован (1939): Дубровачка акӣа и йовеље, књ. ІІІ, св. 2. Београд: СКА.

Reindl-Kiel, Hedda, ,East is East and West is West, and Sometimes the Twain Did Meet Diplomatic Gift Exchange in the Ottoman Empire" u: Imber, Colin - Kiyotaki, Keiko - Murphey Rhoads (2005): Frontiers of Ottoman Studies, vol. II, [ed. Library of Ottoman Studies, 6]. London: I. B. Tauris.

Ricaut Paul (1686): The History of The Present State of the Ottoman Empire. London: Printed for Charles Brome.

Pia Pedani, Maria, „Consoli veneziani nei porti del Mediterraneo in età moderna“ u: Cancila, Rosella (ur.) (2007): Mediterraneo in Armi (secc. XV-XVIII), vol. I-II. Palermo: Quaderni di Mediterranea. 
Самарџић, Никола (1992): Француска и Турска 1687-1691. Београд: Историјски институт CAHУ.

Самарџић, Радован (1959): Дубровник и политичка криза уочи 1683. године, Истиоријски гласник 1-2, 61-92.

Самарџић, Радован (1962): Велики век Дубровника. Београд: Просвета.

Tournefort, Joseph Pitton (1741): A Voyage into the Levant, vol. I-III. London, Printd for D. Midwinter \&c.

Marija Kocić

\section{PORTE'S TREATMENT OF AMBASSADORS OF RAGUSA BY THE END OF FAZIL AHMED-PASHA KÖPRÜLÜ'S VIZIERATE}

\section{SUMMARY}

Diplomatic manner which the Porte implemented during reception of envoys from Ragusa originated from their position. Due to this, Ragusa envoys were deprived of gala ceremony during their first audience, as opposed to what was implemented in the case of ambassadors from England, France and the Netherlands. Ragusa did not appoint permanent ambassadors, and as a result, they did not have a residence in Istanbul. At the same time, their envoys did not have to endure the rage of Ahmed Pasha Köprülü, who ceded many of his duties to his favourites during the last years of his vizierate. The case of Musaip Pasha represents personal wishes, expressed to the extreme, of certain viziers; this quality characterized Porte's relations not only with Ragusa, but with other countries as well. Ahmed - Pasha Köprülü, worn out by old age and water disease, had no further desire to express wilfulness, which especially affected the ambassadors of France for a period of time.

Keywords: Dubrovnik, Ottoman Empire, Ahmed Pasha Köprülü, Constantinople, Edrine 